ekf

\title{
Assessment of efficiency in Visegrad countries and regions using DEA models
}

\author{
Michaela STANÍČKOVÁ, Lukáš MELECKÝ, VŠB-TU Ostrava ${ }^{i}$
}

\begin{abstract}
This paper applies Data Envelopment Analysis (DEA) methods to evaluate the performances of Visegrad Four (V4) countries and their NUTS 2 regions. It analyses the degree of efficiency achieved in individual countries and regions of V4, which is perceived as a reflection of the development potential in the reference period 2000-2010. The theoretical part of the paper is devoted to the fundamental bases of efficiency analysis in the context of performance theory and the methodology of the DEA method. The empirical part measures the effectiveness of the four countries and 35 NUTS 2 regions using six selected DEA models. When applying the DEA method in the analysis, we use selected indicators of inputs and outputs, which are part of the EU's growth strategies. Using the DEA method for efficiency evaluation is preferable because it evaluates a set of factors that determine the degree of economic development. The DEA method is based on the inputs and outputs of used indicators and it evaluates how efficiently countries and regions are able to transform their inputs into outputs. Therefore, the efficiency of countries and regions can be considered to be a mirror of performance. Each country and region is ranked in terms of its effective and ineffective economic positions within V4. The final part of the paper offers a comprehensive comparison of the results obtained using the selected DEA models, namely the CCR model, BCC model and SBM.
\end{abstract}

\section{Keywords}

DEA method, efficiency, model BCC/CCR/SBM, NUTS 2 region, performance, Visegrad four

JEL Classification: C67, C82, R11, Y10

\footnotetext{
${ }^{\text {i }}$ Department of European Integration, Faculty of Economics, VŠB-Technical University of Ostrava, Sokolská 33 , 70121 Ostrava, Czech Republic.

michaela.stanickova@vsb.cz (corresponding author)

This paper was created under SGS project (SP2012/153) of the Faculty of Economics, VŠB-TU Ostrava.
}

\section{Introduction}

The European Union is a heterogeneous unit with significant disparities between its Member States and their regions. Supporting cohesion and balanced development and increasing EU competitiveness are among the EU's key development objectives. The process of European integration is thus guided by striving for two objectives: to foster economic competitiveness and to reduce territorial differences (Molle, 2007). Although the EU is one of the most developed parts of the world with high living standards, there exist huge economic, social and territorial disparities, which negatively affect balanced development across Member States and their regions and thus weaken the
EU's performance in a global context. In relation to the competitiveness objective, performance and efficiency are complementary objectives, which determine the long-term development of countries and regions. The measurement, analysis and evaluation of productivity changes, efficiency and level of competitiveness are controversial topics that have grown in interest among researchers (see e.g. Camanho and Dyson, 2006; Khan and Soverall, 2007).

This paper measures and evaluates the efficiency levels of countries and NUTS 2 regions within the Visegrad Four (V4), i.e. Czech Republic, Hungary, Poland and Slovakia, through the application of selected Data Envelopment Analysis (DEA) models. 
This performance analysis is used for evaluating the quality and potential of national/regional development (with respect to the endowment of national/regional factors). The DEA method is thus a suitable tool for ranking the competitive positions of countries and regions based on efficiency within V4. The application of the DEA method is based on the assumption that the efficiency of V4 countries and regions calculated by the DEA method can be seen as the source of national or regional competitiveness (competitive potential) (see e.g. Staníčková and Melecký, 2012). Measuring the efficiency level of evaluated V4 countries and regions can be based on the procedure scheme in Table 1.

Table 1 Basic scheme of efficiency modelling

Input data analysis

» Pre-processing phase »

» Collection of indicators at a national and regional level »

» Data analysis of indicators in countries and regions »

» Groups of indicators for the input and output of countries and regions $\gg$

DEA modelling

» Basic DEA models at a national and regional level »

» Advanced DEA models at a national and regional level »

» Evaluation of efficiency in countries and regions »

» Interpretation of results »

\section{Theoretical background of efficiency analysis in the context of performance}

In the EU, the process of improving performance and attaining a higher level of competitiveness is difficult because of the heterogeneity of countries and regions in many areas. The concept of competitiveness in the $\mathrm{EU}$ is specific to the inclusion of certain elements of European integration that go beyond purely economic parameters. The economy may be competitive but if society and the environment suffer too much the country would face major difficulties, and vice versa. Therefore, in the long run governments cannot focus only on the economic competitiveness of their countries; instead, they need an integrated approach to govern the country and focus on the broadest aspects that affect competitiveness and thus efficiency (Barrell et al., 2000).

\subsection{Concepts of performance and efficiency}

Performance management is one of the major sources of sustainable national effectiveness, and a systematic understanding of the factors that affect productivity, and subsequently competitiveness, is crucial. In recent years, measuring and evaluating performance as a topic has grown in economic interest, because performance remains one of the basic standards of efficiency evaluation and it is seen as a reflection of country/region success in a wider (international/inter- regional) comparison. Performance is also highly important for many economic subjects (e.g. companies, states, regions) and for the individuals involved in them. Performance comprises both a behavioural and an outcome aspect. It is a multidimensional and dynamic concept like competitiveness. Despite the great relevance of performance and widespread use of this term as an outcome measure in empirical research, however, relatively little effort has been spent on clarifying the performance concept.

In relation to competitiveness and performance, efficiency is a term that has recently come to the forefront of the scientific world. As the world struggles to accommodate the enormous growth in population and to manage the distribution of resources, the effort to make things more efficient has become increasingly more relevant to reach higher competitive potential. Efficiency is a central issue in broker analyses of economic growth, the effects of fiscal policies, the pricing of capital assets, the level of investments, technology changes and production technology and other economic topics and indicators. In a competitive economy, therefore, the issue of efficiency, resp. dynamic efficiency, can be resolved by comparing these economic issues.

Nowadays, efficiency is one of the fundamental criteria for evaluating economic performance and it reflects success in a broader comparison. Organisations (e.g. companies, states, regions) need highly performing units in order to meet their goals, to deliver the products and services they specialise in and to achieve competitive advantage. Low performance and not achieving the goals might be experienced as dissatisfying or even as a failure. Moreover, performance - if it is recognised by other organisations - is often rewarded by benefits, such as a better market position, higher competitive advantage and greater financial condition. Performance is a major - although not the only - prerequisite for future economic and social development and success in a broader comparison.

\subsection{Approaches to efficiency evaluation}

Evaluating efficiency is a main issue of economic research, but this also lacks a mainstream approach. Efficiency evaluation in terms of the differences between countries and regions should be measured through a complex of economic, social and environmental criteria that identify imbalanced areas that cause the main disparities. Currently, quantitative as well as qualitative development at the national level, and especially at the regional level, increases socioeconomic attraction and creates new opportunities, which are fundamental to overcoming disparities and increasing the performances of territories. 
The primary problem in creating an effective evaluation system is establishing clear performance and efficiency standards and priorities at the beginning of the performance cycle. Early research on this problem focused on separate measures for productivity, and there was a failure to combine the measurements of multiple inputs into any satisfactory measure of efficiency. These inadequate approaches included forming an average productivity for a single input (ignoring all other inputs) and constructing an efficiency index in which a weighted average of inputs was compared with output. Responding to these inadequacies of separate indices of labour productivity, capital productivity and so on, Farrell (1957) proposed an activity analysis approach that could more adequately deal with the problem. His measures were intended to be applicable to any productive organisation; in other words, from a workshop to a whole economy (Mohammadi and Ranaei, 2011). Farrell confined his numerical examples and discussion to single output situations, although he was able to formulate a multiple output case. Twenty years after Farrell's model, and building on those ideas, Charnes et al. (1978), responding to the need for satisfactory procedures to assess the relative efficiencies of multiinput/multi-output production units, introduced a powerful methodology, which was subsequently called DEA (Zhu, 2012).

The measurement and evaluation of performance, efficiency and productivity is an important issue for at least two reasons. One is that in a group of units where only a limited number of candidates can be selected, the performance of each must be evaluated in a fair and consistent manner. The other is that as time progresses, better performance is expected. Hence, units with declining performance must be identified in order to make the necessary improvements (Greenaway, Görg and Kneller, 2008). The performances of countries and regions can be evaluated in either a cross-sectional or a time-series manner, and DEA is a useful method for both types of efficiency evaluations (Mohammadi and Ranaei, 2011).

\section{Measuring efficiency using the DEA method}

The EU is aiming to restore the foundations of its competitiveness and economic performance by increasing its growth potential and productivity. The performance analysis provided by the DEA method can be used for evaluating national development efficiency with respect to the national factor endowment of evaluated countries.

\subsection{Theoretical background of the DEA method}

Since DEA was introduced in 1978, researchers in a number of fields have quickly recognised that it is an excellent and easily used methodology for modelling operational processes for performance evaluations. This has been accompanied by other developments. DEA is based on a simple Farrell model (1957) for measuring the effectiveness of units with one input and one output, which was initially expanded in 1978 by Charnes, Cooper and Rhodes (CCR model) and later modified in 1984 by Banker, Charnes and Cooper (BCC model). DEA methods also include advanced additive models, such as the Slack-Based Model (SBM; Tone, 2002) or the Free Disposal Hull and Free Replicability Hull models formulated in 1984 by Deprins, Simar and Tulkens (see Cook and Zhu, 2008).

DEA is a relatively new data-oriented approach for assessing efficiency and evaluating the performance of a set of peer entities called Decision-Making Units (DMUs), which convert multiple inputs into multiple outputs. DEA is thus a multicriteria decisionmaking method for evaluating the effectiveness, efficiency and productivity of homogeneous groups (i.e. DMUs). The definition of a DMU is generic and flexible. DEA allows us to determine the efficiency of DMUs that are mutually comparable (using same inputs and producing same outputs) but show different performances. The efficiency score of a DMU in the presence of multiple input and output factors is defined by equation (1) (Zhu, 2012):

$$
\text { Efficiency }=\frac{\text { weighted sum of outputs }}{\text { weighted sum of inputs }} \text {. }
$$

The aim of the DEA method is to examine whether DMUs are effective by assessing the size and quantity of the resources consumed by the produced outputs (Andresen and Petersen, 1993). Best-practice units are used as a reference for the evaluation of other group units. A DMU is efficient if the observed data correspond to testing whether the DMU is on the imaginary production possibility frontier. All other DMUs are simply inefficient. For every inefficient DMU, DEA identifies a set of corresponding efficient units that can be utilised as benchmarks for improvement. However, DEA is primarily a diagnostic tool and does not prescribe any reengineering strategies to improve the performances of DMUs (Coelli et al., 2005).

In recent years, we have seen a great variety of applications of DEA for evaluating the performances of many different kinds of entities engaged in many different activities. Owing to its low assumption requirements, DEA has also opened up possibilities for use in cases that have been resistant to other approaches because of the complex (often unknown) nature of the relations between multiple inputs and multiple outputs involved in DMUs. It is thus a convenient method for comparing national or regional efficiency as an assumption for the performance of a territory, because it evaluates not only one 
factor, but also a set of different factors that determine the degree of economic development. The DEA analysis of V4 countries and regions is based on a particular set of input and output indicators. Inputs and outputs form the key elements of a system evaluated for every country and regions within V4 in the sense of their effective economic positions. For this purpose, the DEA method can identify the competitive position of each country and region (Melecký, 2011).

\subsection{Fundamental basis of empirical analysis in $\mathrm{V} 4$ countries and regions}

Based on the above facts, DEA analysis can be used in evaluating national/regional development efficiency with respect to national/regional factor endowment. Thus, DEA is in the following analysis applied to four countries and 35 NUTS 2 regions within V4. At first glance, it might seem that V4 is an incomparable group based on the different geographic sizes, populations, regional administrative structures and segmentation, economic performances and levels of economic, social and territorial disparities. However, these countries have (to a certain extent) identical features, such as common historical backgrounds, similar cultural backgrounds, similar traditions and interdependent economic relations. The trends in production and elimination of regional disparities in these countries are also similar. Nevertheless, each country possesses different economic and social conditions at the beginning of the new millennium. This fact is also reflected in the success of the convergence process in achieving the EU's competitiveness level.

In the context of EU performance, efficiency can be measured by the indicators of EU growth strategies (Lisbon strategy - Structural (Lisbon) indicators, Strategy Europe 2020 - Indicators of Europe 2020). The multidimensionality of the indicators of these growth strategies reflects the multiple forces driving economic growth and development. These growth strategies present the trends in other advanced economies for creating a smart, highly productive economy. A highly productive economy is competitive and able to provide high and rising living standards, allowing all members of society to contribute to and benefit from high levels of efficiency (Hančlová et al., 2010).

The efficiency analysis starts by building a database of the indicators of EU growth strategies monitored by Eurostat (2012), namely EU Structural (Lisbon) indicators and indicators of Strategy Europe 2020. To evaluate countries and regions efficiency, we can define a number of similar indicators based on different data. That is why the results are usually inconsistent. A larger number of inputs and outputs can be used for measuring and evaluating the overall effectiveness of countries and regions as well. We select five indicators - three of them are inputs and two outputs - which measure national/regional efficiency and subsequent national/regional competitive potential (see e.g. Staníčková and Skokan, 2012). The reference period is determined by the early adoption and implementation of the Lisbon strategy in 2000 and availability of selected indicators at a territorial level ending in 2010.

It is necessary to discuss the criteria for selecting these indicators. Firstly, we chose one indicator as a representative of each EU growth strategy's dimension. The first input is gross domestic expenditure on $R \& D$ (GERD), which measures the key R\&D investment that supports future competitiveness and results in higher GDP. GERD represents one of the major drivers of economic growth in a knowledge-based economy. Trends in the GERD indicator provide key indications of the future performance and competitiveness and wealth of the EU. This indicator also measures the extent to which evaluated countries are developing economies based on research, knowledge and innovation.

It is obvious that the overall performance of the economy affects the number of people employed in various sectors of it as well as their skills and working ages (20-64 years). Thus, the criterion of employment rate was selected as the second input. This indicator gauges the capacity of an economy to mobilise all human resources to contribute to the economic growth of society. The efficiency and flexibility of the labour market are critical to ensuring that workers are allocated to their most efficient use in the economy and provided with incentives to give their best effort in their jobs.

The third included input is number of students by tertiary education, a new indicator targeted in Strategy Europe 2020. Number of students by tertiary education together with quality higher education and training is crucial for economies that want to move up the value chain beyond simple production processes and products. Today's globalising economy requires countries to nurture pools of well-educated workers who are able to adapt rapidly to their changing environments and the evolving needs of the production system.

There are two outputs in the case of the presented DEA models. Reflected outputs are measured by GDP in purchasing power standards and labour productivity per person employed. GDP is the most important macroeconomic aggregate. This has become the standard measure of economic progress; it is thus the indicator of economic performance and social progress. GDP is also represented as a measure of output or a measure of well-being. Economic growth is an increase in production and consumption of goods and services, and indicated by increasing GDP. 
Similar to GDP, labour productivity shows how much production economically active people, or employed persons in the national economy, have created. The indicator of labour productivity per person employed is closely interrelated with that of employment rate, because they are both related to the labour market. Labour markets must have the flexibility to shift workers from one economic activity to another rapidly and at low cost, and to allow for wage fluctuations without much social disruption.

These indicators are closely interconnected. The capacity of an economy to shift towards more knowledge-intensive higher value-added activities will depend on its capacity to generate new knowledge through better performing innovation and educational systems and the effective use of technologies, including ICT, as much as on the business conditions that facilitate or hinder the ability to bring this new knowledge into the market in a timely and effective manner. Further, policies to enhance labour market participation, employment and social inclusion are closely intertwined, as the best manner to secure social inclusion is by ensuring gainful employment for a large share of the population.

To calculate the economic efficiency of V4 countries and regions we used six selected DEA models:

1. CCR input-oriented model (with multiple inputs and outputs), assuming constant returns to scale (CRS),

2. CCR output-oriented model (with multiple inputs and outputs), assuming CRS,

3. BCC input-oriented model (with multiple inputs and outputs), assuming variable returns to scale (VRS),

4. BCC output-oriented model (with multiple inputs and outputs), assuming VRS,

5. SBM additive model not focusing on input and output (with multiple inputs and outputs), assuming CRS,

6. SBM additive model not focusing on input and output (with multiple inputs and outputs), assuming VRS.

Basic DEA models, primary CCR input/outputoriented models (with multiple inputs and outputs), assume CRS. In 1984, Banker, Charnes and Cooper modified the CCR model, which considers VRS (decreasing, increasing or constant) - BCC input/output-oriented models (with multiple inputs and outputs). VRS can better identify more efficient units. The assumption of VRS provides a more realistic expression of economic reality and factual relations, events and activities existing in countries and regions (Hair and Black, 2009).

The CCR and BCC models evaluate the efficiency of units (in our case, countries and regions) for any number of inputs and outputs. The coefficient of efficiency $(C E)$ is the ratio between the weighted sum of outputs and the weighted sum of inputs. Each country or region selects input and output weights that maximise their efficiency scores. The CE takes values in the interval $\langle 0,1\rangle$. In DEA models aimed at inputs, the CEs of efficient countries or regions (located on the efficient frontier package) always equal 1, while the CEs of inefficient countries or regions are less than 1. In DEA models aimed at outputs, the CEs of efficient countries or regions (located on the efficient frontier package) always equal 1, but the CEs of inefficient countries or regions are greater than 1. DEA also allows us to compute the necessary improvements required in the inefficient country's (region's) inputs and outputs to make it more efficient.

CCR and BCC models are radial, which means that they contain radial variables $\theta_{q}$ (for models aimed at inputs) and $\varphi_{q}$ (for models aimed at outputs). These variables indicate the required level of reduction in all inputs $\left(\theta_{q}\right)$ and the rate of increase of all outputs $\left(\varphi_{q}\right)$ to achieve efficiency. However, CCR and BCC models must focus on the distinction between inputs and outputs. SBM additive models measure directly the effectiveness of using additional variables $\left(\mathbf{s}^{+}\right.$and $\left.\mathbf{s}^{-}\right)$. In the formulation of SBM additive models, it is not necessary to distinguish between a focus on inputs and outputs. In SBM models, the CEs of efficient units always equal 0 , because this is the sum of the additional variables for inputs and outputs $\left(\mathbf{s}^{+}\right.$and $\left.\mathbf{s}^{-}\right)$, which expresses the distance from the efficient frontier. The lower the sum of additional variables for inputs and outputs, the closer the evaluated unit (in our case, country/region) is to the efficient frontier package and the higher its degree of efficiency is, and vice versa (Fiala et al., 2010).

Assuming four countries and 35 NUTS 2 regions within $\mathrm{V} 4$, each with $m$ inputs and $r$ outputs, the relative efficiency score of a test country/region $q$ is obtained by solving equations (2)-(6) (Zhu, 2012).

For CCR input-oriented models (with multiple inputs and outputs) assuming CRS:

$$
\max z=\sum_{i}^{r} u_{i} y_{i q},
$$

on conditions:

$$
\begin{gathered}
\sum_{i}^{r} u_{i} y_{i k} \leq \sum_{j}^{m} v_{j} x_{j k}, k=1,2, \ldots, n, \\
\sum_{j}^{m} v_{j} x_{j q}=1, \\
u_{i} \geq \varepsilon, i=1,2, \ldots, r, \\
v_{j} \geq \varepsilon, j=1,2, \ldots, m .
\end{gathered}
$$

Here $z$ is the CE of unit $U_{q}, u_{i}$ weights are assigned to the $i$-th output, $v_{j}$ weights are assigned to the $j$-th input, $\varepsilon$ represents an infinitesimal constant, $x_{j k}$ is the value 
of the $j$-th input of unit $U_{k}, x_{j q}$ is the value of the $j$-th input of unit $U_{q}, y_{i k}$ is the value of the $i$-th output of unit $U_{k}, y_{i q}$ is the value of the $i$-th output of unit $U_{q}, m$ represent inputs and $r$ represent outputs. All variables have the same meaning in equations (3)-(5).

For CCR output-oriented models (with multiple inputs and outputs) assuming CRS:

$$
\min g=\sum_{j}^{m} v_{j} x_{j q}
$$

on conditions:

$$
\begin{gathered}
\sum_{i}^{r} u_{i} y_{i k} \leq \sum_{j}^{m} v_{j} x_{j k}, k=1,2, \ldots, n, \\
\sum_{i}^{r} u_{i} y_{i q}=1, \\
u_{i} \geq \varepsilon, i=1,2, \ldots, r, \\
v_{j} \geq \varepsilon, j=1,2, \ldots, m .
\end{gathered}
$$

Here, $g$ means the CE of unit $U_{q}$. All variables in equation (3) have the same meaning as in equation (2).

For BCC input-oriented models (with multiple inputs and outputs) assuming VRS:

$$
\max z=\sum_{i}^{r} u_{i} y_{i q}+\mu,
$$

on conditions:

$$
\begin{gathered}
\sum_{i}^{r} u_{i} y_{i q}+\mu \leq \sum_{j}^{m} v_{j} x_{j k}, k=1,2, \ldots n, \\
\sum_{j}^{m} v_{j} x_{j q}=1, \\
u_{i} \geq \varepsilon, i=1,2, \ldots, r, \\
v_{j} \geq \varepsilon, j=1,2, \ldots, m .
\end{gathered}
$$

Here, $\mu$ is a dual variable associated with the convexity condition $\mathbf{e}^{\mathbf{T}} \lambda=1$. All variables in equation (4) have the same meaning as in equation (2).

For BCC output-oriented models (with multiple inputs and outputs) assuming VRS:

$$
\min g=\sum_{i}^{m} v_{j} x_{j q}+v
$$

on conditions:

$$
\begin{gathered}
\sum_{i}^{r} u_{i} y_{i k} \leq \sum_{j}^{m} v_{j} x_{j k}+v, k=1,2, \ldots, n, \\
\sum_{i}^{r} u_{i} y_{q}=1, \\
u_{i} \geq \varepsilon, i=1,2, \ldots, r, \\
v_{j} \geq \varepsilon, j=1,2, \ldots, m, \\
v-\text { arbitrary. }
\end{gathered}
$$

where $v$ is a dual variable associated with the convexity condition $\mathbf{e}^{\mathbf{T}} \boldsymbol{\lambda}=1$. All variables in equation (5) have the same meaning as in equation (2).

For SBM additive models not focusing on input and output (with multiple inputs and outputs):

$$
\max z=\left(\mathbf{e}^{\mathrm{T}} \mathbf{s}^{+}+\mathbf{e}^{\mathrm{T}} \mathbf{s}^{-}\right),
$$

on conditions:

$$
\begin{gathered}
\mathbf{X} \lambda+\mathbf{s}^{-}=\mathbf{x}_{\mathbf{q}}, \\
\mathbf{Y} \boldsymbol{\lambda}-\mathbf{s}^{+}=\mathbf{y}_{\mathbf{q}}, \\
\mathbf{e}^{\mathrm{T}} \lambda \leq=\geq 1, \\
\lambda, \mathbf{s}^{+}, \mathbf{s}^{-} \geq 0 .
\end{gathered}
$$

where $z$ is the CE of unit $U_{q} ; \mathbf{s}^{+}$, and $\mathbf{s}^{-}$are the vectors of the additional variables for inputs and outputs; $\lambda$ represents the vector of weights assigned to individual units, $\lambda \geq 0, \lambda=\left(\lambda_{1}, \lambda_{2}, \ldots, \lambda_{n}\right) ; \mathbf{e}^{\mathbf{T}} \lambda$ is the convexity condition according to the nature of returns to scale, i.e. for CRS $\mathbf{e}^{\mathrm{T}} \lambda=$ arbitrary, for VRS $\mathbf{e}^{\mathrm{T}} \lambda=1 ; x_{q}$ means the value of the input of unit $U_{q}$; and $y_{q}$ means the value of the output of unit $U_{q}$.

DEA models are solved using software tools based on solving linear programming problems, e.g. Solver in MS Excel, such as the DEA Frontier (Cooper et al., 2004; Cook and Zhu, 2008; Zhu, 2012), which is used in this paper to evaluate the efficiency of V4 countries and regions.

\section{Efficiency analysis of V4 countries and regions using the CCR, BCC and SBM models}

The initial assumption that areas achieving the best results in efficiency are those best at converting inputs into outputs and therefore having the greatest performance and productive potential was partly confirmed by the analysis, as shown in the following evaluation.

\subsection{Evaluation of national efficiency in V4 coun- tries using the CCR, BCC and SBM models}

In the case of national efficiency evaluation, we found that the DEA models provided comparable results in all V4 countries. Table 2 presents a comparison of the efficiency evaluation of the V4 countries using the CCR, BCC and SBM models. At a national level, it is evident that the levels of efficiency of individual countries are on average lower in CCR models than they are in BCC models. This fact confirms the theory that in BCC models with VRS, CEs reach higher values and a higher number of evaluated DMUs are classified as effective. This was also confirmed in SBM models with VRS by a higher number of evaluated units identified as effective compared with SBM models with CRS.

The overall evaluation of efficiency of V4 countries also shows that the best results were achieved by two (CCR model) and three (BCC model) countries during the period 2000-2010. These countries were effective in both $C C R$ and $B C C$ input/output-oriented models, as well as in SBM models; therefore, according to our hypothesis, they should have the greatest 
development potential. Efficient countries are highlighted by dark grey in Table 2. There are the Czech Republic and Slovakia for $C C R$ models, as well as Hungary in the case of $B C C$ models. They are also the Czech Republic and Slovakia in the case of the SBM model with CRS, and also Hungary for the SBM model with VRS.

Efficient countries are followed by a group of countries that are slightly inefficient. These countries do not achieve an efficiency score of 1 in the $C C R$ and $B C C$ models or have a low sum of the values of the additional variables in $S B M$ models, but their efficiency indices reached consistently highly effective values close to the reference period (coloured in light grey in Table 2). These countries are Hungary and Poland in the $C C R$ models, and Poland in the BCC models. In the case of the SBM model with CRS, it is also Poland and Hungary, and Poland in the SBM model with VRS.

Table 3 shows the positions of V4 countries within selected models in terms of the order of achieved average values of CEs in the CCR and BCC models or the sum of the values of the additional variables in the SBM models over the period 2000-2010. The overall evaluation of V4 countries shows that the best results, in terms of efficiency in all used DEA models, were achieved by the Czech Republic and Slovakia. In second place is Hungary, which was evaluated as highly effective, as it reached full efficiency in the BCC models and in the SBM model with VRS, and a high level of efficiency in the CCR models and in the SBM model with CRS. Poland is ranked in third place. It had the lowest values of CEs in the CCR and BCC models, but a higher sum of the values of the additional variables in the SBM model with CRS. None of the V4 countries was classified as inefficient.

\subsection{Evaluation of regional efficiency in V4 NUTS 2 regions using the $\mathrm{CCR}, \mathrm{BCC}$ and $\mathrm{SBM}$ models}

The best results are traditionally achieved by economically powerful regions (in most cases), which were efficient during the whole reference period. This means that the outputs achieved were greater than those incurred inputs. Efficient V4 NUTS 2 regions are coloured in dark grey in Table 5. There are the cohesion regions in the Czech Republic - CZO1 (Prague), CZO2 (Central Bohemia) and CZ04 (Northwest). In Poland, one of the effective provinces is region PL42 (Zachodniopomorskie) in the CCR, BCC and SBM models. In the BCC models and SBM model with VRS, PLA3 (Lubuskie) is also an effective region. In Slovakia, SKO1 (Bratislava region) is effective in the CCR, BCC and SBM models. The best final position is thus reached by the performances of regions with agglomerations of major cities and regions in their surroundings. These regions, in the frame of our hypothesis, could be those with the best competitive potential and scope for further development. The analysis at the regional level also showed that in Hungary no region was found to be effective during the reference period.

Efficient regions are followed by a group of regions that are slightly inefficient (coloured by light grey in Table 5 in the Appendix. These include HU1O (Central Hungary) and HU22 (Western Transdanubia) in the CCR models, HU1O (Central Hungary) and

Table 2 Comparison of efficiency results in the CCR, BCC and SBM models for the V4 countries

\begin{tabular}{|l|l|c|c|c|c|c|c|}
\hline \multirow{2}{*}{ Code } & \multirow{2}{*}{ Country } & $\begin{array}{c}\text { Input-oriented } \\
\text { CCR model }\end{array}$ & $\begin{array}{c}\text { Output-oriented } \\
\text { CCR model }\end{array}$ & $\begin{array}{c}\text { Input-oriented } \\
\text { BCC model }\end{array}$ & $\begin{array}{c}\text { Output-oriented } \\
\text { BCC model }\end{array}$ & $\begin{array}{c}\text { SBM CRS } \\
\text { model }\end{array}$ & $\begin{array}{c}\text { SBM VRS } \\
\text { model }\end{array}$ \\
\cline { 3 - 8 } & CE* & CE* & CE* $^{*}$ & CE* & CE* $^{*}$ & CE* $^{*}$ \\
\hline CZ0 & Czech Republic & 1.000 & 1.000 & 1.000 & 1.000 & 0 & 0 \\
\hline PL0 & Hungary & 0.997 & 1.003 & 1.000 & 1.000 & 21,052 & 0 \\
\hline SK0 & Slovand & 0.941 & 1.069 & 0.999 & 1.002 & $1,355,702$ & 170,612 \\
\hline
\end{tabular}

Note: * CE means average efficiency rate of the country in the period 2000-2010

Table 3 Ranking of V4 countries in selected DEA models by CE value

\begin{tabular}{|c|c|c|c|c|c|c|c|c|}
\hline \multirow[t]{2}{*}{ Code } & $\begin{array}{c}\text { Input- } \\
\text { oriented } \\
\text { CCR model }\end{array}$ & $\begin{array}{c}\text { Output- } \\
\text { oriented } \\
\text { CCR model }\end{array}$ & $\begin{array}{c}\text { Input- } \\
\text { oriented } \\
\text { BCC model }\end{array}$ & $\begin{array}{c}\text { Output- } \\
\text { oriented } \\
\text { BCC model }\end{array}$ & $\begin{array}{c}S B M C R S \\
\quad \text { model }\end{array}$ & $\begin{array}{c}\text { SBM VRS } \\
\text { model }\end{array}$ & \multirow{2}{*}{$\begin{array}{l}\text { Average } \\
\text { rank of } \\
\text { country* }\end{array}$} & \multirow{2}{*}{$\begin{array}{c}\text { Absolute } \\
\text { rank of } \\
\text { country }^{*}\end{array}$} \\
\hline & Rank & Rank & Rank & Rank & Rank & Rank & & \\
\hline $\mathrm{CZ0}$ & 1 & 1 & 1 & 1 & 1 & 1 & 1.0 & 1. \\
\hline HU0 & 2 & 2 & 1 & 1 & 2 & 1 & 1.5 & 2. \\
\hline PL0 & 3 & 3 & 2 & 2 & 3 & 2 & 2.5 & 3. \\
\hline SK0 & 1 & 1 & 1 & 1 & 1 & 1 & 1.0 & 1. \\
\hline
\end{tabular}

Note: * Average and absolute ranking of V4 countries is based on their rank in selected DEA models in the period 2000-2010 
HU31 (North Hungary) in the BCC models, HU22 (Western Transdanubia) in the SBM model with CRS and HU31 (North Hungary) in the SBM model VRS. In Poland, there are highly effective provinces such as PL22 (Slaskie), PL43 (Lubuskie) and PL52 (Opolskie) in the CCR models and PL22 (Slaskie) and PL52 (Opolskie) in the BCC models. In Poland, highly effective provinces were PL43 (Lubuskie) and PL52 (Opolskie) in the SBM model with CRS and PL52 (Opolskie) in the SBM model with VRS.

Other regions were classified as ineffective in the CCR, BCC and SBM models; these are highlighted by italics in Table 5 in the Appendix. The least efficient NUTS 2 region in the Czech Republic was CZ06 (Southeast) in all used DEA models. In Hungary, the least efficient NUTS 2 regions were HU1O (Central Hungary) in the SBM models and HU33 (Southern Great Plains) in the CCR and BCC models. In Poland, the least efficient NUTS 2 provinces were PL31 (Lubelskie) in the CCR and BCC models and PL12 (Mazowieckie) in the SBM models. In Slovakia, the least efficient NUTS 2 region was SKO2 (Western Slovakia) in all used DEA models.

At a regional level, the DEA method faced anomalies in the final efficiency classification of selected NUTS 2 regions in the values of CEs in the CCR and $\mathrm{BCC}$ models and in the sum of the values of the additional variables in the SBM models. There are essentially NUTS 2 regions - CZO4 (North West) in the Czech Republic, SKO4 (Eastern Slovakia) in Slovakia and PL22 (Slaskie), PL33 (Swietokrzyskie) and PL42 (Zachodniopomorskie) in Poland. These regions were evaluated as highly competitive. Anyway, in this case it is not possible to confirm the initial hypothesis of efficiency being a mirror of competitive potential. The DEA method evaluates the volume of inputs for given outputs, which in the case of these regions seems to be effective, although they generally belong to the less than average or average developed regions within $\mathrm{V} 4$ countries.

Table 6 in the Appendix shows the highest positions of individual V4 regions over the period 20002010. The overall evaluation of individual V4 regions shows that the best results, in terms of efficiency in all used DEA models, were by CZO1 (Prague), CZO2 (Central Bohemia) and CZ04 (Northwest) in the Czech Republic. These regions ranked in first place among the 35 NUTS 2 regions during 2000-2010. In Poland, PL42 (Zachodniopomorskie) and in Slovakia SKO1 (Bratislava region) were ranked in first place among all the evaluated regions followed by PL43 (Lubuskie) and PL52 (Opolskie). All these regions reached full efficiency in all the used DEA models during the reference period. Table 6 in the Appendix also shows the lowest positions of all 35 NUTS 2 regions. In 26th place (i.e., third worst) is PL11 (Lodzkie) followed by PL31 (Lubelskie) and PL22 (Slaskie).

\section{Conclusion}

Competitiveness, performance and efficiency are complementary objectives that determine the longterm development of countries and regions. These are also concepts that cannot be avoided in economic theory and practice. Competitiveness, performance and efficiency can be evaluated only if we use existing concepts of these terms or selected mainstream ones. Because there is no mainstream concept of competitiveness, performance and efficiency evaluation, especially at a regional level, there is space for an alternative approach in this area. It is necessary to note that using different evaluation approaches generates different results. This is logical and predictable. It cannot be expected that different approaches lead to identical conclusions about the level of competitiveness, performance and efficiency. Many methods and approaches to competitiveness, performance and efficiency evaluation are (to a certain extent) incomparable, and therefore their results must be taken into account individually. A certain degree of individual assessment should therefore apply in terms of the concrete results (and order) of individual V4 countries, especially their NUTS 2 regions. National efficiency, as a mirror of performance, is based on the competitive potential of individual regions.

This paper evaluated the efficiency of V4 countries and their NUTS 2 regions in the reference period 2000-2010 using a specific multicriteria approach the DEA method. The analysis evaluated the degree of the relevance of six selected DEA models for measuring the efficiency of V4 countries and regions. These models generated relatively comparable results, both at a national and at a regional level.

The initial assumption was partly confirmed through analysis both at the national and at the regional level. At the national level, the analysis showed that two of the V4 countries, namely the Czech Republic and Slovakia, were fully effective during the whole period. These countries thus effectively utilise their competitive advantages and have the highest development potential. Poland and Hungary were classified as highly effective. These countries achieved high efficiency in more than one year during the reference period, and therefore also show a high development potential. Specifically, Hungary was assessed as fully effective in the BCC models and SBM model with CRS. In the CCR models and SBM model with VRS, Hungary was assessed as highly effective. Poland was evaluated as highly effective in all models during the analysis. 
At the regional level, five NUTS 2 regions were evaluated as the most effective in the CCR models during the period 2000-2010. Another five were evaluated as highly effective, because their CEs reached values approaching a level of efficiency equal to 1 during the reference period. Another 25 NUTS 2 regions were categorised as inefficient and having less competitive potential. Of these, four were evaluated as the least effective. In the BCC models, six NUTS 2 regions were evaluated as the most effective during the reference period, with five highly effective and 24 inefficient (of which four were assessed as the least effective). In the SBM model with CRS, five NUTS 2 regions were most effective within the reference period. Another three were evaluated as highly effective and four as least effective. In the SBM model with VRS, six NUTS 2 regions were evaluated as most effective, another two were highly effective and four least effective. Table 4 shows the number of NUTS 2 regions that were evaluated as effective, highly effective or inefficient, in a breakdown by the used DEA models.

At the regional level, the DEA method faced anomalies in the final efficiency classification of five NUTS 2 regions and thus it was not possible to confirm the initial hypothesis of efficiency being a mirror of competitive potential. The DEA method evaluates the volume of inputs for given outputs, which in the case of these regions seems to be effective, although they generally belong to the less than average or average developed regions within V4 countries. This fact could be a prerequisite for further research on the evaluation of national/regional efficiency using other advanced DEA models.

Based on the presented DEA analysis, we found that in evaluated countries there is a distinct gap between economic and social standards, so differences remain. Regarding the findings and analysis, each country and region can decide whether it had a level of efficiency and productivity trend increase during the time period. By having this information and dividing efficiency and subsequent productivity into its elements, the basic trend in efficiency level and productivity trend can be observed.
According to the used DEA models, it is necessary to note that noticeable efficiency and productivity increases were achieved in most evaluated countries and regions, thus strengthening performance during the reference period. Further, most countries and regions experienced declines in their performances (outputs decline as a result of declines in inputs) as a result of the recent economic crisis, which has seriously threatened the achievement of sustainable development in the field of competitiveness. The crisis has underscored the importance of competitiveness, supporting the economic environment to enable national economies to better absorb shocks and ensure solid performance in the future.

\section{References}

ANDERSEN, P., PETERSEN, N.C. (1993). A procedure for ranking efficient units in data envelopment analysis. Management Science 39(10): 1261-1264. http://dx.doi.org/10.1287/mnsc.39.10.1261

BARRELL, R., MASON, G., O'MAHONY, M. (2000). Productivity, Innovation and Economic Growth. Cambridge: Cambridge University Press.

CAMANHO, A.S., DYSON, R.G. (2006). Data envelopment analysis and Malmquist indices for measuring group performance. Journal of Productivity Analysis 26(1): 35-49.

http://dx.doi.org/10.1007/s11123-006-0004-8

CHARNES, A., COOPER, W., RHODES, E. (1978). Measuring the efficiency of decision making units. European Journal of Operational Research 2(6): 429 444.

http://dx.doi.org/10.1016/0377-2217(78)90138-8

COELLI, T.J., RAO, D.S.P., O’DONNELL, C.J., BATTESE, G.E. (2005). An Introduction to Efficiency and Productivity Analysis. New York: Springer.

COOK, W.D., ZHU, J. (2008). Data Envelopment Analysis: Modelling Operational Processes and Measuring Productivity. Boston: Kluwer Academic Publishers.

COOPER, W.W., SEIFORD, L.M., ZHU, J. (2004). Data Envelopment Analysis: Models and Interpretations. Boston: Kluwer Academic Publisher.

Table 4 Classification of V4 regions in terms of efficiency levels

\begin{tabular}{|l|c|c|c|c|c|c|}
\hline \multirow{2}{*}{ Efficiency } & $\begin{array}{c}\text { Input-oriented } \\
\text { CCR model }\end{array}$ & $\begin{array}{c}\text { Output-oriented } \\
\text { CCR model }\end{array}$ & $\begin{array}{c}\text { Input-oriented } \\
\text { BCC model }\end{array}$ & $\begin{array}{c}\text { Output-oriented } \\
\text { BCC model }\end{array}$ & $\begin{array}{c}\text { SBM CRS } \\
\text { model }\end{array}$ & $\begin{array}{c}\text { SBM VRS } \\
\text { model }\end{array}$ \\
\cline { 2 - 8 } & $\begin{array}{c}\text { Number of } \\
\text { regions }\end{array}$ & $\begin{array}{c}\text { Number of } \\
\text { regions }\end{array}$ & $\begin{array}{c}\text { Number of } \\
\text { regions }\end{array}$ & $\begin{array}{c}\text { Number of } \\
\text { regions }\end{array}$ & $\begin{array}{c}\text { Number of } \\
\text { regions }\end{array}$ & $\begin{array}{c}\text { Number of } \\
\text { regions }\end{array}$ \\
\hline Hill effective & 5 & 5 & 6 & 6 & 5 & 6 \\
\hline Ineffective & 5 & 5 & 5 & 5 & 3 & 2 \\
\hline
\end{tabular}


FARRELL, M.J. (1957). The measurement of productivity efficiency. Journal of the Royal Statistical Society 120(3): 253-290.

http://dx.doi.org/10.2307/2343100

FIALA, P. et al. (2010). Operační výzkum - nové trendy. Praha: Professional Publishing.

GREENAWAY, D., GÖRG, H., KNELLER, R. (2008). Globalization and Productivity. Cheltenham: Edward Elgar Publishing Limited.

HAIR, J.F., BLACK, W.C., BABIN, B.J., ANDERSON, R.E. (2009). Multivariate Data Analysis. New Jersey: Prentice Hall.

HANČLOVÁ, J. et al. (2010). Macroeconometric Modeling of the Czech Economy and Selected EU Economies. Ostrava: VŠB-TU Ostrava.

KHAN, J., SOVERALL, W. (2007). Gaining Productivity. Kingston: Arawak Publications.

MELECKÝ, L. (2011). Approaches to regional competitiveness evaluation in the Visegrad four countries. In: Mathematical Models and Methods in Modern Science - $2^{\text {nd }}$ International Conference on Development, Energy, Environment, Economics 2011. Puerto De La Cruz: WSEAS Press, 184-189.
MOHAMMADI, A., RANAEI, H. (2011). The application of DEA based Malmquist productivity index in organizational performance analysis. International Research Journal of Finance and Economics 6(62): 68-76.

MOLLE, W. (2007). European Cohesion Policy. London: Routledge.

STANÍČKOVÁ, M., MELECKÝ, L. (2012). Hodnocení efektivnosti zemí a regionů Visegrádské čtyřky prostřednictvím vybraných modelů analýzy obalu dat. In: MEKON 2012. Ostrava: VŠB-TU Ostrava, 1-17.

STANÍČKOVÁ, M., SKOKAN, K. (2012). Evaluation of the EU member states efficiency by data envelopment analysis method. International Journal of Mathematical Models and Methods in Applied Sciences 2(6): 349-357.

\section{Additional sources}

EUROSTAT (2012). Eurostat: Statistics. [Online], accessed at 21. 02. 2012. Available at: <http://epp.eurostat.ec.europa.eu/portal/page/portal/sta tistics/themes>.

ZHU, J. (2012). Manual DEA Frontier - DEA Add-In for Microsoft Excel, [Online], accessed at 31. 05. 2012. Available at: <http://www.deafrontier.net/>. 


\section{Appendix}

Table 5 Comparison of efficiency results in selected DEA models: CCR, BCC and SBM for V4 NUTS 2 regions

\begin{tabular}{|c|c|c|c|c|c|c|c|}
\hline \multirow[t]{2}{*}{ Code } & \multirow[t]{2}{*}{ Region } & $\begin{array}{c}\text { Input } \\
\text { oriented } \\
\text { CCR model }\end{array}$ & $\begin{array}{c}\text { Output } \\
\text { oriented } \\
\text { CCR model }\end{array}$ & $\begin{array}{c}\text { Input } \\
\text { oriented } \\
\text { BCC model }\end{array}$ & $\begin{array}{c}\text { Output } \\
\text { oriented } \\
\text { BCC model }\end{array}$ & $\begin{array}{c}S B M C R S \\
\text { model }\end{array}$ & $\begin{array}{c}S B M \text { VRS } \\
\text { model }\end{array}$ \\
\hline & & $\mathrm{CE}^{*}$ & $\mathrm{CE}^{*}$ & $\mathrm{CE}^{*}$ & $\mathrm{CE}^{*}$ & $\mathrm{CE}^{*}$ & $\mathrm{CE}^{*}$ \\
\hline CZ01 & Prague & 1.000 & 1.000 & 1.000 & 1.000 & 0 & 0 \\
\hline $\mathrm{CZ02}$ & Central Bohemia & 1.000 & 1.000 & 1.000 & 1.000 & 0 & 0 \\
\hline $\mathrm{CZ03}$ & Southwest & 0.751 & 1.257 & 0.889 & 1.324 & 17,180 & 16,193 \\
\hline $\mathrm{CZO4}$ & Northwest & 1.000 & 1.000 & 1.000 & 1.000 & 0 & 0 \\
\hline $\mathrm{CZ05}$ & Northeast & 0.767 & 1.248 & 0.908 & 1.301 & 16,299 & 16,011 \\
\hline CZ06 & Southeast & 0.596 & 1.565 & 0.835 & 1.613 & 55,406 & 55,260 \\
\hline CZ07 & Central Moravia & 0.764 & 1.246 & 0.914 & 1.290 & 16,129 & 15,233 \\
\hline CZ08 & Moravian Silesian & 0.760 & 1.249 & 0.928 & 1.209 & 20,742 & 15,720 \\
\hline HU10 & Central Hungary & 0.941 & 1.048 & 0.989 & 1.017 & 116,090 & 37,360 \\
\hline HU21 & Central Transdanubia & 0.856 & 1.154 & 0.958 & 1.111 & 11,366 & 7,356 \\
\hline HU22 & Western Transdanubia & 0.914 & 1.081 & 0.965 & 1.086 & 10,022 & 7,176 \\
\hline HU23 & South Transdanubia & 0.796 & 1.234 & 0.969 & 1.071 & 21,971 & 5,696 \\
\hline HU31 & Northern Hungary & 0.820 & 1.176 & 0.996 & 1.012 & 19,759 & 1,121 \\
\hline HU32 & Northern Great Plains & 0.642 & 1.477 & 0.976 & 1.072 & 34,746 & 8,349 \\
\hline HU33 & Southern Great Plains & 0.611 & 1.550 & 0.911 & 1.361 & 35,753 & 19,540 \\
\hline PL11 & Lódzkie & 0.544 & 1.690 & 0.885 & 1.689 & 123,986 & 112,113 \\
\hline PL12 & Mazowieckie & 0.811 & 1.168 & 0.933 & 1.189 & 394,149 & 341,274 \\
\hline PL21 & Malopolskie & 0.489 & 1.827 & 0.853 & 1.894 & 191,856 & 180,728 \\
\hline PL22 & Slaskie & 0.940 & 1.041 & 0.993 & 1.030 & 98,160 & 57,949 \\
\hline PL31 & Lubelskie & 0.442 & 2.082 & 0.848 & 2.254 & 101,554 & 89,136 \\
\hline PL32 & Podkarpackie & 0.560 & 1.650 & 0.880 & 1.786 & 65,891 & 52,667 \\
\hline PL33 & Swietokrzyskie & 0.898 & 1.082 & 0.974 & 1.162 & 19,807 & 16,299 \\
\hline PL34 & Podlaskie & 0.662 & 1.437 & 0.863 & 1.464 & 43,971 & 34,457 \\
\hline PL41 & Wielkopolskie & 0.732 & 1.298 & 0.896 & 1.330 & 157,843 & 148,898 \\
\hline PL42 & Zachodniopomorskie & 1.000 & 1.000 & 1.000 & 1.000 & 0 & 0 \\
\hline PL43 & Lubuskie & 0.997 & 1.003 & 1.000 & 1.000 & 984 & 0 \\
\hline PL51 & Dolnoslaskie & 0.866 & 1.118 & 0.980 & 1.080 & 125,797 & 76,279 \\
\hline PL52 & Opolskie & 0.951 & 1.059 & 0.977 & 1.048 & 5,489 & 4,212 \\
\hline PL61 & Kujawsko-Pomorskie & 0.814 & 1.212 & 0.949 & 1.193 & 65,744 & 50,638 \\
\hline PL62 & Warminsko-Mazurskie & 0.789 & 1.209 & 0.974 & 1.240 & 43,072 & 26,810 \\
\hline PL63 & Pomorskie & 0.827 & 1.154 & 0.946 & 1.158 & 71,255 & 48,873 \\
\hline SK01 & Bratislava region & 1.000 & 1.000 & 1.000 & 1.000 & 0 & 0 \\
\hline SK02 & Western Slovakia & 0.734 & 1.310 & 0.876 & 1.342 & 33,476 & 31,622 \\
\hline SK03 & Central Slovakia & 0.789 & 1.246 & 0.912 & 1.246 & 26,928 & 17,908 \\
\hline SK04 & Eastern Slovakia & 0.789 & 1.224 & 0.934 & 1.219 & 24,955 & 12,634 \\
\hline
\end{tabular}

Note: * Coefficient of efficiency is average efficiency rate of V4 NUTS 2 region in period 2000-2010 
Table 6 Ranking of NUTS 2 V4 regions in selected DEA models by values of CEs

\begin{tabular}{|c|c|c|c|c|c|c|c|c|}
\hline \multirow[t]{2}{*}{ Code } & $\begin{array}{c}\text { Input } \\
\text { oriented } \\
\text { CCR model }\end{array}$ & $\begin{array}{c}\text { Output } \\
\text { oriented } \\
\text { CCR model }\end{array}$ & $\begin{array}{c}\text { Input } \\
\text { oriented } \\
\text { BCC model }\end{array}$ & $\begin{array}{c}\text { Output } \\
\text { oriented BCC } \\
\text { model }\end{array}$ & $\begin{array}{c}S B M C R S \\
\text { model }\end{array}$ & $\begin{array}{c}S B M V R S \\
\text { model }\end{array}$ & \multirow[t]{2}{*}{$\begin{array}{l}\text { Average } \\
\text { rank of } \\
\text { region* }\end{array}$} & \multirow[t]{2}{*}{$\begin{array}{c}\text { Absolute } \\
\text { rank of } \\
\text { region* }\end{array}$} \\
\hline & Rank & Rank & Rank & Rank & Rank & Rank & & \\
\hline CZ01 & 1 & 1 & 1 & 1 & 1 & 1 & 1.0 & 1. \\
\hline CZ02 & 1 & 1 & 1 & 1 & 1 & 1 & 1.0 & 1. \\
\hline CZ03 & 19 & 19 & 22 & 21 & 8 & 12 & 16.8 & 19. \\
\hline CZ04 & 1 & 1 & 1 & 1 & 1 & 1 & 1.0 & 1. \\
\hline CZ05 & 16 & 17 & 20 & 20 & 7 & 11 & 15.2 & 16. \\
\hline CZ06 & 25 & 25 & 29 & 26 & 20 & 23 & 24.7 & 25. \\
\hline CZ07 & 17 & 16 & 17 & 19 & 6 & 9 & 14.0 & 13. \\
\hline CZ08 & 18 & 18 & 16 & 15 & 11 & 10 & 14.7 & 15. \\
\hline HU10 & 4 & 4 & 4 & 3 & 26 & 19 & 10.0 & 8. \\
\hline HU21 & 9 & 9 & 11 & 10 & 5 & 6 & 8.3 & 6. \\
\hline HU22 & 6 & 6 & 10 & 9 & 4 & 5 & 6.7 & 5. \\
\hline HU23 & 14 & 15 & 9 & 6 & 12 & 4 & 10.0 & 8. \\
\hline HU31 & 11 & 11 & 2 & 2 & 9 & 2 & 6.2 & 4. \\
\hline HU32 & 23 & 23 & 7 & 7 & 16 & 7 & 13.8 & 12. \\
\hline HU33 & 24 & 24 & 19 & 24 & 17 & 15 & 20.5 & 22. \\
\hline PL11 & 27 & 27 & 23 & 27 & 27 & 27 & 26.3 & 26. \\
\hline PL12 & 13 & 10 & 15 & 13 & 31 & 30 & 18.7 & 20. \\
\hline PL21 & 28 & 28 & 27 & 29 & 30 & 29 & 28.5 & 28. \\
\hline PL22 & 5 & 3 & 3 & 4 & 24 & 24 & 10.5 & 9. \\
\hline PL31 & 29 & 29 & 28 & 30 & 25 & 26 & 27.8 & 27. \\
\hline PL32 & 26 & 26 & 24 & 28 & 22 & 22 & 24.7 & 25. \\
\hline PL33 & 7 & 7 & 8 & 12 & 10 & 13 & 9.5 & 7. \\
\hline PL34 & 22 & 22 & 26 & 25 & 19 & 18 & 22.0 & 23. \\
\hline PL41 & 21 & 20 & 21 & 22 & 29 & 28 & 23.5 & 24. \\
\hline PL42 & 1 & 1 & 1 & 1 & 1 & 1 & 1.0 & 1. \\
\hline PL43 & 2 & 2 & 1 & 1 & 2 & 1 & 1.5 & 2. \\
\hline PL51 & 8 & 8 & 5 & 8 & 28 & 25 & 13.7 & 11. \\
\hline PL52 & 3 & 5 & 6 & 5 & 3 & 3 & 4.2 & 3. \\
\hline PL61 & 12 & 13 & 12 & 14 & 21 & 21 & 15.5 & 17. \\
\hline PL62 & 15 & 12 & 8 & 17 & 18 & 16 & 14.3 & 14. \\
\hline PL63 & 10 & 9 & 13 & 11 & 23 & 20 & 14.3 & 14. \\
\hline SK01 & 1 & 1 & 1 & 1 & 1 & 1 & 1.0 & 1. \\
\hline SK02 & 20 & 21 & 25 & 23 & 15 & 17 & 20.2 & 21. \\
\hline SK03 & 15 & 16 & 18 & 18 & 14 & 14 & 15.8 & 18. \\
\hline SK04 & 15 & 14 & 14 & 16 & 13 & 8 & 13.3 & 10. \\
\hline
\end{tabular}

Note: * Average and absolute ranking of V4 NUTS 2 regions is based on their rank in DEA models in period 2000-2010 